\title{
Brain-derived neurotrophic factor and its clinical implications
}

\author{
Siresha Bathina ${ }^{1}$, Undurti N. Das ${ }^{1,2}$
}

\author{
'Bio-Science Research Center, Gayatri Vidya Parishad College of Engineering, \\ Visakhapatnam, India \\ 2UND Life Sciences, USA
}

Submitted: 21 July 2014

Accepted: 5 August 2014

Arch Med Sci 2015; 11, 6: 1164-1178

DOI: $10.5114 /$ aoms.2015.56342

Copyright @ 2015 Termedia \& Banach

\begin{abstract}
Brain-derived neurotrophic factor (BDNF) plays an important role in neuronal survival and growth, serves as a neurotransmitter modulator, and participates in neuronal plasticity, which is essential for learning and memory. It is widely expressed in the CNS, gut and other tissues. BDNF binds to its high affinity receptor TrkB (tyrosine kinase B) and activates signal transduction cascades (IRS1/2, PI3K, Akt), crucial for CREB and CBP production, that encode proteins involved in $\beta$ cell survival. BDNF and insulin-like growth factor-1 have similar downstream signaling mechanisms incorporating both p-CAMK and MAPK that increase the expression of pro-survival genes. Brain-derived neurotrophic factor regulates glucose and energy metabolism and prevents exhaustion of $\beta$ cells. Decreased levels of BDNF are associated with neurodegenerative diseases with neuronal loss, such as Parkinson's disease, Alzheimer's disease, multiple sclerosis and Huntington's disease. Thus, BDNF may be useful in the prevention and management of several diseases including diabetes mellitus.
\end{abstract}

Key words: brain-derived neurotrophic factor, $\beta$ cell, signal transduction, diabetes mellitus, Alzheimer's disease, neurotransmission.

\section{Introduction}

Brain-derived neurotrophic factor (BDNF) is one of the neurotrophic factors that support differentiation [1], maturation [2], and survival of neurons in the nervous system [3] and shows a neuroprotective effect under adverse conditions, such as glutamatergic stimulation, cerebral ischemia, hypoglycemia, and neurotoxicity [4]. BDNF stimulates and controls growth of new neurons from neural stem cells (neurogenesis) $[5,6]$, and BDNF protein and mRNA have been identified in most brain areas including the olfactory bulb, cortex, hippocampus, basal forebrain, mesencephalon, hypothalamus, brainstem and spinal cord. The levels of BDNF are decreased in many neurodegenerative diseases such as Parkinson's disease (PD) [7], multiple sclerosis (MS) [8] and Huntington's disease [9]. Besides the neuroprotective effect, BDNF plays a major role in energy homeostasis. The BDNF administration peripherally or intracerebroventricularly (ICV) suppresses energy intake and reduces body weight [10].

\author{
Corresponding author: \\ Dr. Undurti N. Das MD, FAMS, \\ FRSC \\ UND Life Sciences \\ 2020 S360th St, \#K-202 \\ Federal Way, WA 98003, USA \\ Phone: 216-231-5548 \\ E-mail: undurti@hotmail.com
}




\section{Origin of BDNF}

BDNF is a member of the neurotrophin family of growth factors along with nerve growth factor (NGF); neurotrophins-3 (NT-3), NT4/5 and NT-6. BDNF is synthesized in the endoplasmic reticulum (ER) as a 32-35 kDa precursor protein (pro BDNF) that moves through the Golgi apparatus and trans-Golgi network (TGN). In the presence of lipid raft associated sorting receptor carboxy peptidase $\mathrm{E}$ (CPE), pro-BDNF is sorted by vesicles and subsequently transported into activity-dependent secretion by post-synaptic dendrites (Figure 1). The terminal domain of pro-BDNF is cleaved by a distinct protein convertase enzyme to form $13 \mathrm{kDa}$ biologically active mature BDNF (mBDNF) [10-12].

\section{Structure of BDNF}

BDNF has close structural homology to NGF and shares about $50 \%$ amino acid identity with NGF, NT-3 and NT-4/5. Each neurotrophin consists of a non-covalently linked homodimer with a signal peptide following the initiation codon and pro-region containing an $\mathrm{N}$-linked glycosylation site [10-12]. In rats, the BDNF gene is located on chromosome 11 and is controlled by multiple activity-dependent and tissue-specific promoters I, II, III, IV; CAMP response-element binding protein (CREB) and upstream stimulatory factor-1/2 (USF-1/2) regulate promoters I and III, and calcium responsive transcription factor (CaRF) mediates transcription by binding to promoter III. All exons that have been defined in humans are also expressed in mouse and rat, except for hu- man exons VIIB and VIII. The rat BDNF gene has been suggested to undergo cryptic splicing within exon II to form IIA, IIB and IIC genes [13-15]. The mouse BDNF gene has eight exons containing separate promoters upstream of each exon and one 3' exon encodes the mature BDNF protein. Multiple promoters determine tissue-specific expression of the BDNF transcript [16]. Human BDNF structure is closely related to rat and mouse BDNF (Figure 2). Eight distinct mRNAs are transcribed, with transcripts containing exons I-III expressed predominantly in brain and exon IV found in lung and heart. In situ hybridization experiments have revealed that BDNF mRNA is strongly expressed in the brain. The BDNF expression levels are low during fetal development, markedly increase after birth, and then decrease in adults [17-19].

\section{Mechanism of action}

\section{BDNF receptors}

The high affinity receptor for BDNF and NT-4/5 is tropomyosin receptor kinase $B$ (TrkB), for NGF it is TrkA, and for NT-3 it is TrkC. TrkB exists in two isoforms:

- The full length receptor glycoprotein (gp145TrkB) (M. Wt $145 \mathrm{kDa}$ ) and

- Truncated form gp95TrkB (M. Wt 95 kDa) lacking tyrosine kinase domain and the LNGFR (low affinity nerve growth factor receptor, also known as p75 NTR).

p75 NTR has been implicated in both pro- and anti-trophic processes such as neurite growth and apoptosis. BDNF and gp145TrkB are widely and abundantly expressed in the brain. The receptors

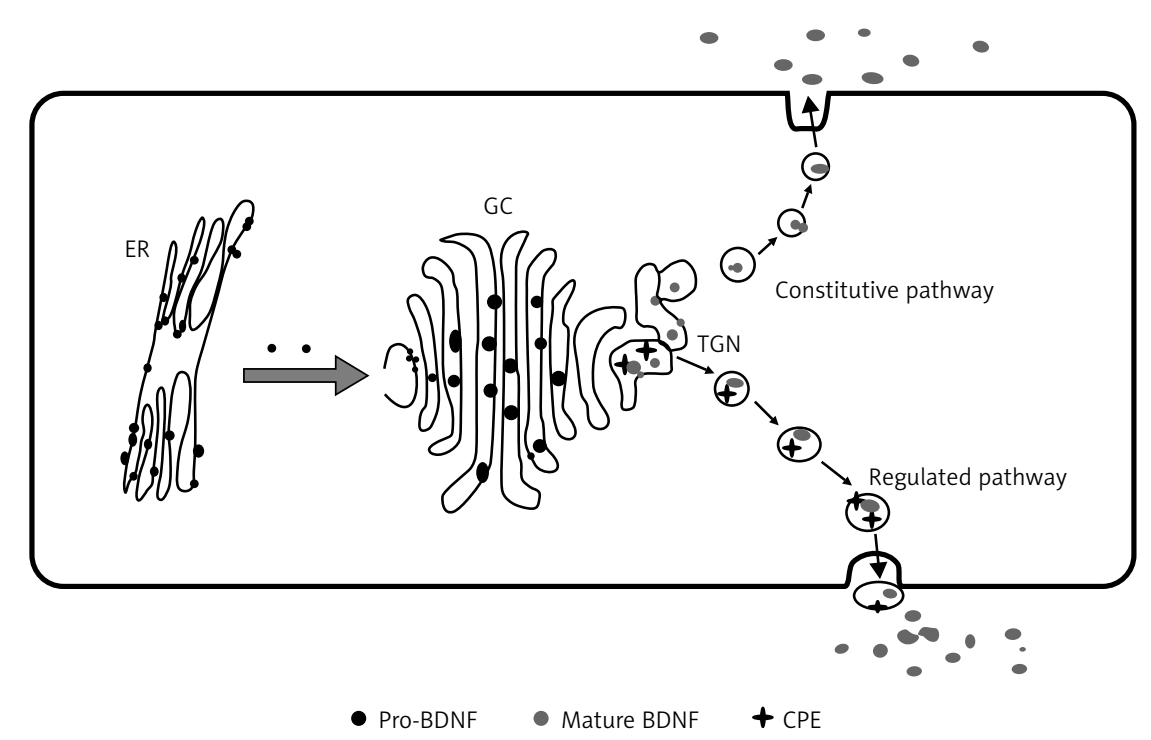

Figure 1. The above figure illustrates the fact of origin of pro-BDNF in endoplasmic reticulum (ER), which is later transported to the Golgi complex (GC) and then to the trans-Golgi network (TGN). From here in the regulated pathway, by the action of CPE and convertase, 13 KDa mature BDNF (mBDNF) is formed and released outside the plasma membrane. This figure is adapted from ref. [13] 


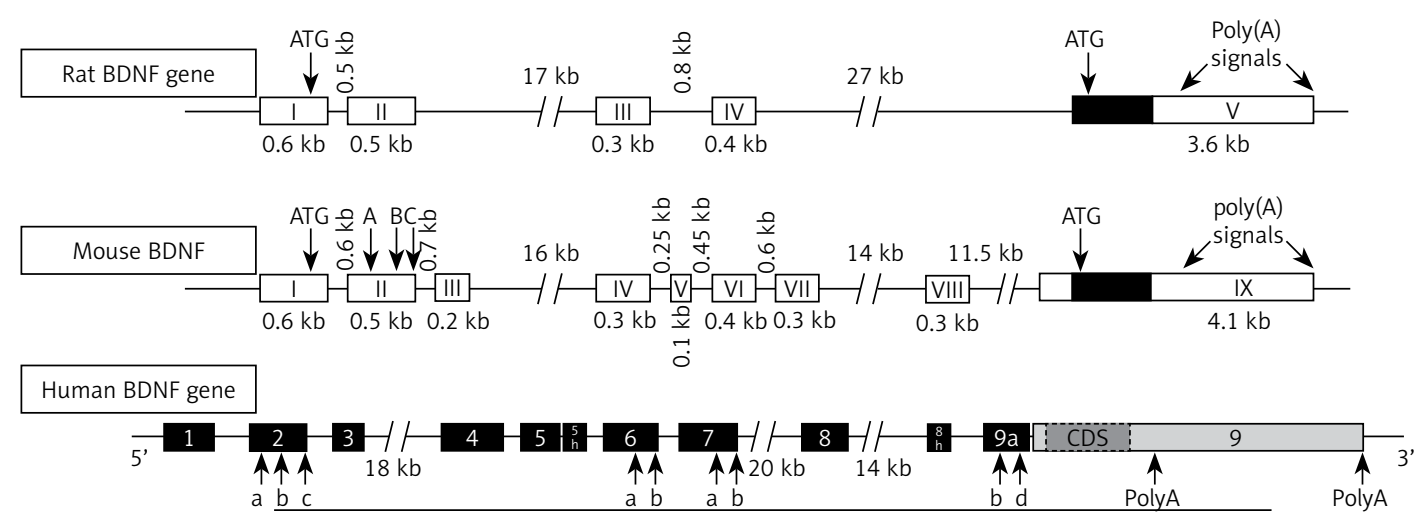

Figure 2. Gene structure of BDNF. Note the presence of four promoters in rat and 9 promoters in mouse. Each of the driving transcripts of BDNF mRNAs containing one of the four $5^{\prime}$ non-coding exons (I, II, III, IV) in promoters is later spliced to the common 3' protein coding exon. Human BDNF structure and its splicing variant are seen above with arrows indicating alternative polyadenylation sites (PolyA) in the $3^{\prime}$-UTR and internal alternative splice sites in exons 2, 6, 7 and 9a (letters a, b, c and d) [18]. Arrangement of introns and exons on BDNF genes is determined by analyzing genomic and mRNA sequence using bioinformatics, RACE, and RT-PCR [17]

for BDNF are present in cells of the spinal cord and grey matter of the spinal cord [20].

\section{Activation of TrkB}

Neurotrophin signaling regulates cell survival, proliferation, the fate of neural precursors, and axon and dendrite growth through TrkB receptors. Neurotrophic tyrosine kinase in humans is encoded by the NTRK2 gene. TrkB has an extracellular domain with many sites of glycosylation, a unique transmembrane segment and an intracellular domain characterized by Trk activity. Upon activation several small $G$ proteins, including Ras as well as MAP kinase, PI3-kinase and phospholipase-C- $\gamma$ (PLC- $\gamma$ ) pathways are regulated. The activation of TrkB is the quickest event ( $2 \mathrm{~min}$ ), and deactivation occurs within 30 min after activation in the spinal cord [20]. Trk receptor-mediated signaling is controlled through expression of intermediates in these signaling pathways that regulate localization of different signaling constituents [21-23].

\section{Activation of secondary messengers}

The cellular actions of neurotrophins are mediated through the activation of the Trk family of receptors TrkA-C and the p75 neurotrophin receptor. The large pre-synaptic p75 NTR has the dual role of modulating Trk receptor binding, Ras-mediated activation of ERK and neurite outgrowth and activating c-jun N-terminal kinase (JNK), leading to apoptosis in a variety of neurons. The secondary messengers which are activated in the spinal cord by BDNF signaling include the MAP/ERK pathway, proto-oncogene c-fos and nitric oxide (NO)-producing neurons [24-26].

\section{Signaling cascade in BDNF}

BDNF (ligand) activation of tyrosine residues results in activation of different intracellular pathways, as shown in Figure 3, leading to neural plasticity, neurogenesis, stress resistance and survival of the cell. This suggests comparative flexibility of Trk receptors in terms of pro-survival function. Thus, BDNF signaling pathways activate one or both of the transcription factors CREB and CREB-binding protein (CBP) that regulate expression of genes encoding proteins involved in neural plasticity, stress resistance and cell survival [27-30].

\section{Ras/MAPK/ERK pathway}

When a ligand (BDNF) binds to the TrkB receptor, it results in dimerization and auto-phosphorylation of tyrosine residues to form a docking site for src-homology 2-domain containing adaptor protein (Shc) and phospholipase C (PLC). Once Shc is docked with the receptor and bound to adapter protein Grb2 by guanine nucleotide-releasing factor SOS, Ras activates the following signaling pathways: Ras/MAPK-ERK pathway, PI3-K pathway and PLC pathway. Ras is linked to Grb2 by the guanine nucleotide-releasing factor SOS. MAPK/ ERK is essential for neurogenesis and promotes survival in two ways: by induction of prosurvival genes and inhibition of proapoptotic (BAD) proteins [31, 32].

\section{IRS-1/PI3K/AKT pathway}

As shown in Figure 3, other pathways involved in the action of BDNF include activation of insulin receptor substrate-1 (IRS-1/2), PI-3K and protein kinase B (Akt). Ras suppresses apoptosis via PI3K; $\mathrm{PI3K}$ activates Akt, which sequesters pro-apoptotic proteins in the cytoplasm away from their transcriptional targets [33]. It is known that inhibition of any portion of the Ras-PI3K-Akt pathway significantly reduces survival of sympathetic neurons in 


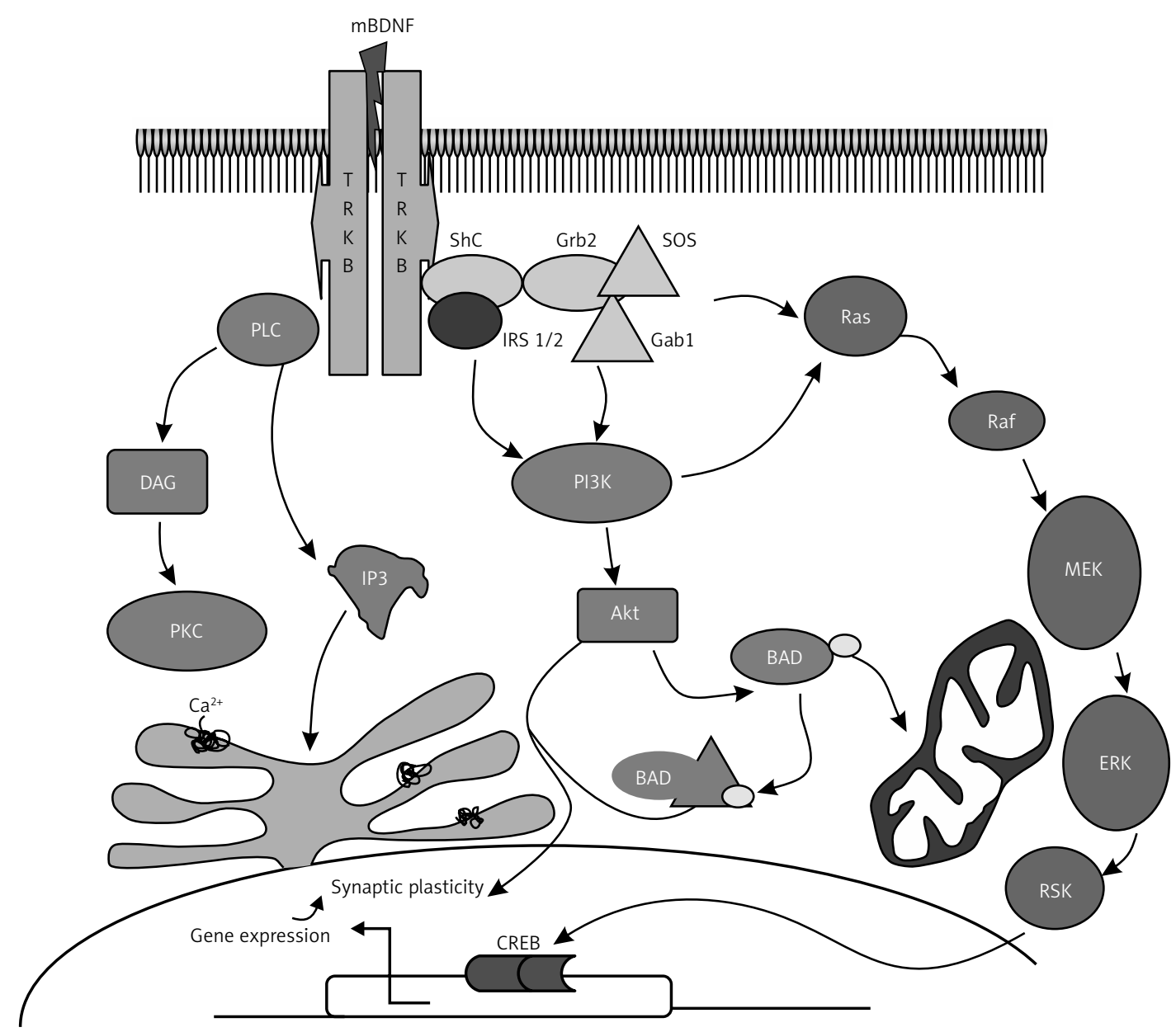

Figure 3. Signaling pathway of BDNF. BDNF binds to its high-affinity receptor tyrosine kinase B (TrkB), resulting in the recruitment of proteins that activate three different signal transduction cascades. One cascade involves sequential activation of insulin receptor substrate-1 (IRS-1/2), phosphatidylinositol-3-kinase (PI-3K) and protein kinase B (Akt). The second is the activation of Shc/Grb2, Ras, Raf, mitogen-activated protein kinase kinases (MEKs) and extracellular signal regulated kinases (ERKs). The third cascade involves phospholipase C (PLC), inositol $(1,4,5)$-trisphosphate [Ins $(1,4,5) \mathrm{P} 3]$, diacylglycerol (DAG) and protein kinase C (PKC). BDNF signaling pathways activate one or more transcription factors (CAMP-response-element-binding protein (CREB) and CREB-binding protein (CBP) that regulate expression of genes encoding proteins involved in neural plasticity, stress resistance and cell survival. This figure is adapted and modified from refs. [32] and [33]

culture in the presence of NGF, implying that the PI3K pathway plays a crucial role in activation of pro-survival genes responsible for cell survival [34].

\section{PLC/DAG/IP3 pathway}

The adapter protein PLC- $\gamma$ is phosphorylated once BDNF docks with the Trk receptor and this leads to breakdown of membrane lipids to inositol 1,4,5 triphosphate (IP3), which promotes an increase in intracellular calcium concentration and diacylglycerol (DAG) $[35,36]$. DAG, in turn, regulates protein kinase $C$, which is required for the MAPK/ ERK signal implicated in neurite outgrowth [37-39].

\section{Agonism of BDNF action}

BDNF mRNA expression is regulated by neuronal activity since epileptogenic activation of glutamatergic synapses increased the expression of BDNF mRNA in slices of rat hippocampus [40, 41]. Increase in synaptic activity induced by AMPA ( $\alpha$-amino-3-hydroxy-5-methyl-4-isoxazolepropionic acid) receptor agonists produced a transient elevation in mRNA levels encoding BDNF and TrkB in the hippocampus and cortex [42]. Light stimulation increased BDNF mRNA in the visual cortex, osmotic stimulation enhanced BDNF mRNA in the hypothalamus, and whisker stimulation increases BDNF mRNA expression in the somatosensory barrel cortex [43, 44]. Electrical stimuli that induce long-term potentiation (LTP) in the hippocampus, a cellular model of learning and memory, increased BDNF and NGF expression [45]. Physical exercise increases NGF and BDNF expression in the hippocampus [46], which may explain its beneficial action in improving memory and prevent 
the development of Alzheimer's disease. BDNF interacts with estrogen to induce neuropeptide-Y (NPY) and together the trio (BDNF-NPY-estrogen) regulates the function of the hippocampus [47].

\section{Antagonism of BDNF action}

Blockade of glutamate receptors or stimulation of the GABAergic (gamma-amino butyric acid) system reduced BDNF mRNA level in the hippocampus [48, 49]. Bozzi et al. [50] demonstrated that an increase or a decrease of neuronal activity can enhance or reduce BDNF expression. Consistent with these observations, light-induced physiological activity enhanced the expression of BDNF mRNA in the visual cortex and monocular deprivation elicited a striking decrease in BDNF mRNA in the visual cortex corresponding to the deprived eye. Anti-BDNF antiserum and the TrkB-IgG construct have been successful to antagonize the action of BDNF in neuropathic pain and inflammatory hypersensitivity models [51]. These findings demonstrate the potential for antibody-mediated TrkB agonism as a potential therapeutic approach to enhance retinal ganglion cells' (RGC) survival after optic nerve injury. Eibl et al. [52] reported that Y1036, a potential multipotent neurotrophin antagonist, altered molecular topology (surface charge density) and acted against BDNF and NGF by preventing NT-induced receptor activation and downstream signaling via the p44/42 MAPK pathway. Furthermore, endogenous production of nitric oxide (NO) downregulated BDNF secretion in hippocampal neurons by activating a cyclic guanosine monophosphate (cGMP)-dependent signal transduction pathway leading to downregulation of $\mathrm{Ca}^{2+}$ release from IP3-sensitive intracellular stores by protein kinase $G$ [53].

\section{Plasma levels of BDNF}

In healthy volunteers, mean plasma BDNF level was found to be $\sim 92.5 \mathrm{pg} / \mathrm{ml}(8.0-927.0 \mathrm{pg} / \mathrm{ml})$. It was higher in women, and decreased with advancing age in both genders [54]. BDNF is widely distributed in various regions of the brain, and aids in survival, support and function of neurons. Other sources of BDNF include the lungs, heart, spleen, gastrointestinal tract and liver. Apart from these, BDNF was found to be expressed in fibroblasts, vascular smooth muscle cells, and thymic stroma [55]. Studies of Lommatzsch et al. [56] confirmed that levels of BDNF in the urinary bladder, lung, and colon were higher than those found in the brain or skin. A positive correlation between blood levels of BDNF and diastolic blood pressure, total cholesterol, low-density lipoprotein (LDL) cholesterol, adipose tissue mass, body mass index and triglyceride was reported. It was suggested that women with low plasma BDNF levels have increased mortality risk [54-57]. This is supported by the observation that a significant reduction in plasma levels of BDNF in females correlated with advancing age and body weight $[58,59]$.

\section{Functions of BDNF}

\section{Neurogenesis}

One of the earliest identified in vivo functions of BDNF is its role to promote survival of peripheral sensory neurons during development of the brain. It was reported that exogenous application of BDNF resulted in increased dendritic length and complexity of pyramidal neurons in the developing visual cortex in a layer-specific manner, suggesting that BDNF not only enhanced neuronal growth but also modulated a specific pattern in dendritic growth. Furthermore, inhibition of spontaneous electrical activity, synaptic transmission, or L-type calcium channels prevented increase in dendritic growth elicited by exogenous BDNF, indicating that neurons must be active enough to respond to growth-promoting action of BDNF [60-62].

In a central nervous system trauma model, using adult rat retinal ganglion cells (RGC), it was observed that in vivo injection of BDNF enhanced neuronal survival by activating the TrkB, MAPK and PI3K-PKB pathways and inhibited caspase-3induced apoptosis. Neurogenesis in the hypothalamus was enhanced by continuous application of BDNF for 12 days. Dietary restriction enhanced neuronal growth in the adult mouse hippocampus, indicating that energy balance is an important factor that can modulate neural growth [63-66].

\section{Synaptic plasticity}

BDNF is involved in the regulation of activity-dependent synaptic plasticity by pre- and post-synaptic mechanisms $[67,68]$. BDNF is essential for pre-synaptic vesicle cycling, which is dependent on NMDA (N-methyl D-aspartate) receptor activation in cultured neocortical neurons of BDNF-knockout mice [69]. This paracrine (retrograde messenger) role of BDNF was later confirmed, and it was shown that application of BDNF to hippocampal sections restored spine actin polymerization and LTP (longterm potentiation) stability in rats [70]. Furthermore, BDNF levels not only increased NMDA levels and intracellular calcium concentrations [71] but also relieved $\mathrm{Mg}^{2+}$ block of NMDA receptors [72], promoting long-term changes to synaptic activity. Reduction of TrkB and BDNF secretion reduced LTP induction [73]. Thus, BDNF is involved in NMDA receptor trafficking by increasing calcium influx [74], which leads to post-synaptic BDNF release that, in turn, increases pre-synaptic vesicle cycling, which enhances LTP and synaptic plasticity [75]. 


\section{Actions on cardiac and endothelial cells}

Neurotrophins promote angiogenesis and control survival of adult endothelial cells (EC), vascular smooth muscle cells (VSMC) and cardiomyocytes. It was reported that BDNF promoted therapeutic neovascularization via the TrkB receptor, whereas low-affinity receptor p75 NTR not only induced apoptosis of endothelial cells and vascular smooth muscles but also impaired angiogenesis. Studies performed in a murine BDNF knockout model revealed that NT-3 and BDNF are involved in the formation of heart and myocardial vasculature. TrkB receptors expressed on endothelial cells activate two major signaling pathways, ERK/MAPK and PI3-kinase/AKT, to promote EC survival [76-79]. In addition, AKT activated endothelial nitric oxide (NO) synthase, which contributes to vascular relaxation; this may account for its cardiovascular protective action [78, 80, 81].

\section{Role in inflammation and immunity}

Elevated levels of neurotrophins (NTs) may contribute to the development of bronchial hy- perreactivity (BHR), a hallmark of allergic asthma, which is confirmed from the observation that release of NTs occurred from immune cells including B-lymphocytes, eosinophils, mast cells and macrophages [82]. It is likely that upon stimulation with antigen (Ag), CD4+ $T$ cells produce BDNF by truncated gp95TrkB (expressed in non-neuronal tissues). BDNF may act as a mediator between airway inflammatory events and neuronal changes that occur during the induction of allergic asthma by enhancing airway smooth muscle contraction and mucus hypersecretion by facilitating the release of acetyl choline and plasma extravasation (Figure 4). On the other hand, in neuro-inflammatory diseases such as multiple sclerosis, there may occur enhanced production of BDNF, which may show neuro-protective activity due to its immunomodulatory action. Thus, BDNF can be used as a therapeutic strategy in detection and prevention of neurological inflammatory disorders [82-84].

\section{Lipid metabolism}

In 1995, it was reported that BDNF affects energy metabolism following intracerebroventricular

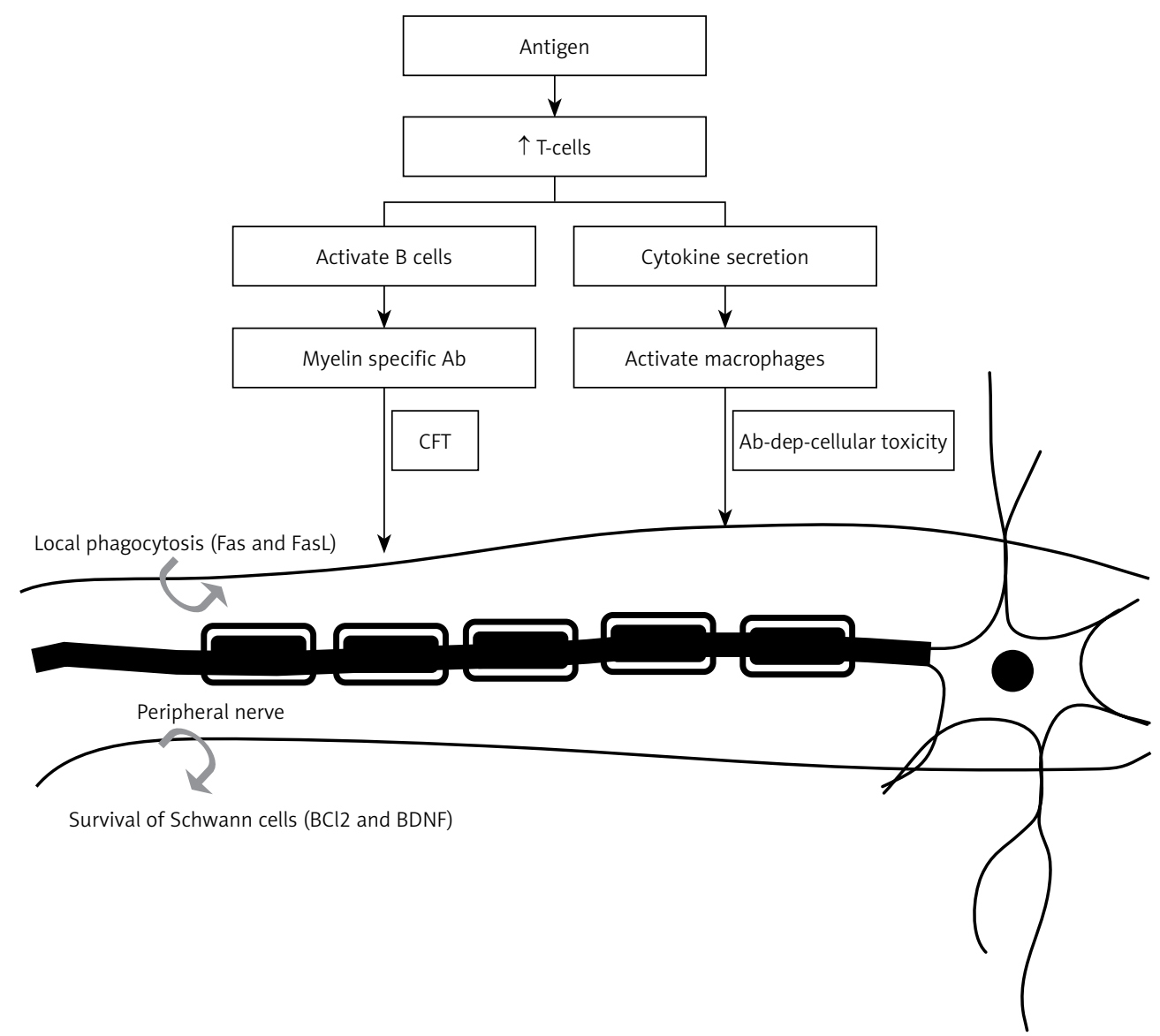

Figure 4. Role of BDNF in neural degeneration diseases such as multiple sclerosis. The antigen once it crosses the blood-brain barrier stimulates the production of T cells, which, in turn, activate B cells and macrophages. Damage to nerve fibers may result from either complement fixation or antibody-dependent cell-mediated immunity, resulting in multiple sclerosis. Neuroinflammatory reactions may also trigger neuroprotective events such as secretion of BDNF and anti-apoptotic Bcl2 that may explain the therapeutic role of BDNF in multiple sclerosis. This figure is adapted from refs. [82-84] 
(ICV) administration, which leads to decreased energy intake and body weight loss in rats. This action of BDNF was found to be associated with a dose-dependent increase in serotonin turnover, nerve cell survival and adaptive plasticity [85].

BDNF showed a positive correlation with low-density lipid (LDL) cholesterol, total cholesterol and triglycerides [86]. BDNF treatment of diabetic animals resulted in a decrease of plasma glucose, non-esterified fat, phospholipids and liver weight, along with an increase in $\beta$-oxidation, peroxisome proliferator activator receptor (PPAR- $\alpha$ ) activation and level of fibroblast growth factor [87]. TrkB activation is essential for appetite regulation and energy homeostasis. It was reported that dietary omega-3 fatty acids normalize BDNF levels (Figure 5), reduce oxidative damage and improve learning ability after traumatic brain injury [88].

These results emphasize the possible interaction between dietary polyunsaturated fatty acids and brain BDNF that may be relevant to energy homeostasis. Exposure to cytotoxic agents activates phospholipid-hydrolase enzymes PLA2 and

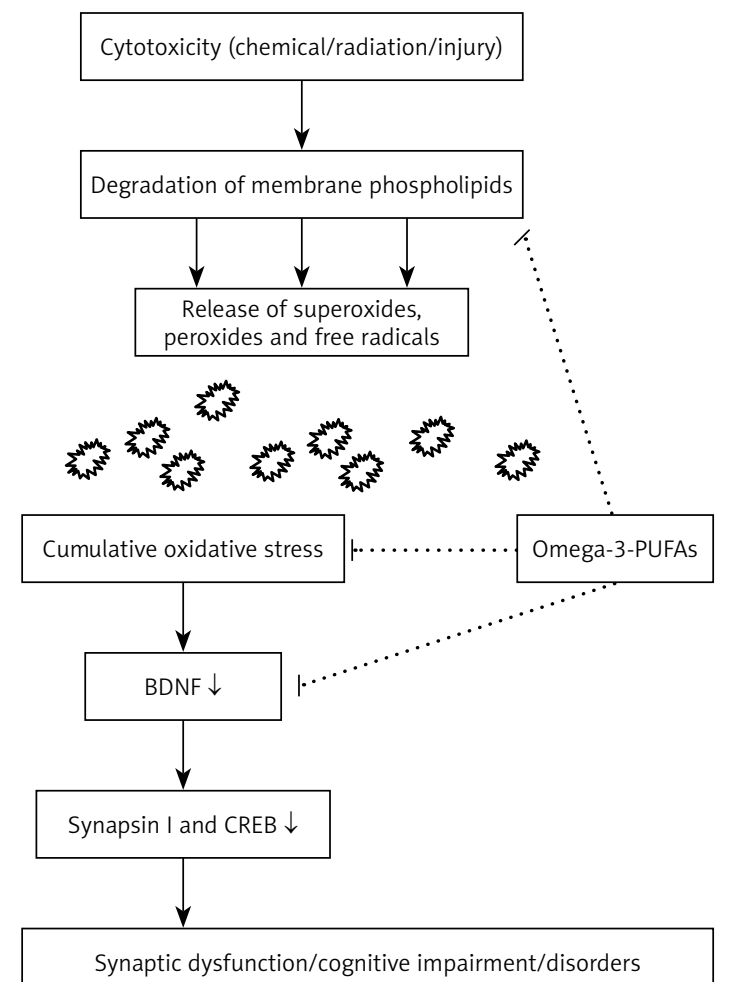

Figure 5. Interaction between omega 3-fatty acids and BDNF that may underlie their cytoprotective actions. Mechanism of cytoprotection may involve: a) prevention of degradation of membrane phospholipids; b) reduction of oxidative stress that helps maintain synaptic plasticity; and c) normalization of levels of BDNF and its downstream effectors synapsin I and CREB, which are important in learning, memory and LTP. This figure is adapted and modified from refs. [89-91]
PLC that cause damage to membrane phospholipases, which, in turn, results in cumulative oxidative stress and subsequent neuronal dysfunction. BDNF facilitates synaptic transmission and regulates gene expression by increasing levels of synapsin I [89] and CREB release, which helps in the maintenance of synaptic plasticity. Docosahexaenoic acid (DHA) has been shown to have anti-oxidant activity and enhance LTP, which may account for its ability to improve learning and memory. Molecular docking studies using a bioinformatics approach revealed that polyunsaturated fatty acids (PUFAs) and their metabolites bind to BDNF and exert an allosteric effect on the TrkB binding pocket, thereby promoting the neurotrophic activity cascade. Furthermore, BDNF interacts with several other neuropeptides, including melanocortin [90, 91], leptin [92], corticotrophin-releasing hormone (CRH) $[93,94]$ and thyrotropin-releasing hormone (TRH) [95] to maintain synergistic action in collaboration with them. Reduced BDNF levels in either conditionally homozygous or heterozygous gene knockout mice were found to develop hyperphagia, obesity and resistance to insulin and leptin $[96,97]$. These studies suggest that interaction between BDNF and PUFAs may play an important role in the pathogenesis of obesity, type 2 diabetes mellitus and metabolic syndrome.

\section{BDNF in type-2 diabetes mellitus}

BDNF has been implicated in the regulation of food intake and body weight both in experimental animals and humans. For instance, systemic administration of BDNF decreased non-fasted blood glucose in obese, non-insulin-dependent diabetic C57BLKS-Lepr(db)/lepr(db) (db/db) mice, with a concomitant decrease in body weight [98]. The effect of BDNF on non-fasted blood glucose levels is not caused by decreased food intake but was found to be due to improvement in blood glucose control, an effect that persisted for weeks after cessation of BDNF treatment. BDNF reduced hepatomegaly present in $d b / d b$ mice, reduced liver glycogen and reduced liver enzyme activity in serum, supporting the involvement of liver tissue in the mechanism of action of BDNF $[99,100]$.

Further support for the role of BDNF in diabetes mellitus is evident from the observation that once or twice per week administration (70 mg/kg/wk) to $d b / d b$ mice for 3 weeks significantly reduced blood glucose concentrations and hemoglobin $\mathrm{A}_{1 \mathrm{c}}\left(\mathrm{HbA}_{1 \mathrm{c}}\right)$ compared to controls. These results suggest that BDNF not only reduced blood glucose concentrations but also restored systemic glucose balance, indicating the possibility that BDNF could be a novel hypoglycemic agent even with treatment as infrequently as once per week [101]. Furthermore, in tracerebroventricular (ICV) administration of BDNF 
lowered blood glucose, increased pancreatic insulin content, enhanced thermogenesis and norepinephrine turnover, and increased uncoupling protein-1 mRNA expression in the interscapular brown adipose tissue of $d b / d b$ mice. This evidence indicates that BDNF activates the sympathetic nervous system and thus regulates energy expenditure in obese diabetic animals [102].

The role of BDNF in type 2 diabetes mellitus is further supported by the observation that plasma levels of BDNF were decreased in humans with type 2 diabetes mellitus independently of obesity, and inversely associated with fasting plasma glucose, but not with insulin [103]. When output of BDNF from the human brain was studied, output was inhibited when blood glucose levels were elevated, whereas when plasma insulin was increased while maintaining normal blood glucose, the cerebral output of BDNF was not inhibited. These results indicate that high levels of glucose, but not insulin, inhibited the output of BDNF from the human brain. These results emphasize that low levels of BDNF accompany impaired glucose metabolism, and decreased BDNF may be a factor involved in type 2 diabetes mellitus [104].

\section{Mechanism(s) involved in the cytoprotective action of BDNF in type 2 diabetes mellitus}

BDNF not only regulated glucose and energy metabolism but also prevented exhaustion of the pancreas in diabetic mice by maintaining the histologic cellular organization of $\beta$ cells and non- $\beta$ cells in pancreatic islets and restoring the level of insulin-secreting granules in $\beta$ cells [105] and thus ameliorated diabetes in experimental animals [106]. These actions of BDNF suggest that it could protect pancreatic $\beta$ cells. The possible mechanism(s) involved in this cytoprotective action of BDNF could be attributed to its binding to the high-affinity receptor TrkB, resulting in the recruitment of proteins that activate IRS-1/2, $\mathrm{PI}-3 \mathrm{~K}$ and protein kinase $\mathrm{B}(\mathrm{Akt})$. These actions result in activation of one or more transcription factors (CREB and CBP) that regulate expression of genes encoding proteins involved in neural plasticity, stress resistance and cell survival. Furthermore, BDNF and IGF-I have similar downstream signaling mechanisms, incorporating both p-CAMKII (calcium/calmodulin protein kinase II) and p-MAPKII (phosphorylated mitogen-activated protein kinase II) signaling cascades [107, 108], which promote cell survival by a dual mechanism consisting of posttranslational modification and inactivation of a component of the cell death machinery and increased transcription of pro-survival genes [109]. In an extension of this study, it was noted that two chemically distinct inhibitors of PI-3K, wortmannin and LY294002, reduced PI-3K activation by IGF-1 and inhibited its survival-promoting activity, suggesting that $\mathrm{PI}-3 \mathrm{~K}$ is necessary for IGF-1-mediated survival. Ultimately death resulting from PI 3-kinase blockade is accompanied by DNA fragmentation, a hallmark of apoptosis [110]. It is likely that BDNF may have actions similar to IGF-1 in producing its cytoprotective actions on pancreatic $\beta$ cells (Figure 6 ).

BDNF seems to be involved in the beneficial action of exercise, which is known to be of use in the prevention and management of obesity, type 2 diabetes mellitus and other features of metabolic syndrome. It was found that moderate exercise increased both basal and end exercise plasma BDNF levels in young healthy men, which was found to be associated with a decrease in insulin resistance [111]. It was reported that the common variation of BDNF (rs4074134) is associated with type 2 diabetes mellitus independently of obesity in the Chinese Han population and the same variant also showed an effect on plasma glucose concentration, body mass index (BMI) and insulin sensitivity [112]. This was further supported by the observation that decreased serum BDNF was decreased in Chinese patients with type 2 diabetes mellitus [113]. Thus, exercise seems to have the ability to enhance circulating levels of BDNF, which are decreased in obesity and type 2 diabetes mellitus, and thus exert beneficial actions. Since BDNF is present in both the gut and the brain, it is likely that increased serum BDNF levels reported after exercise are derived from the brain and gut. Our recent studies revealed that BDNF is not only able to prevent cytotoxic action of chemicals such as alloxan and streptozotocin against pancreatic $\beta$ cells but is also able to enhance their proliferation (unpublished data). Thus, increased BDNF likely to be secreted by the gut during exercise may actually act on pancreatic $\beta$ cells not only to improve their survival but also to enhance their proliferation.

\section{BDNF in neurological disorders}

The ability of BDNF to augment neurogenesis [60-66] and improve synaptic plasticity [67-75], as discussed above, implies that it may have a role in some neurological conditions such as Alzheimer's disease, dementia and autism. In fact, it has been suggested that decreased serum BDNF levels may have a role in the pathophysiology of cognitive deficits noted in patients with type 2 diabetes mellitus [114]. BDNF levels were significantly lower in patients with schizophrenia who had lower cognitive scores than controls, suggesting that BDNF may be involved in the pathophysiology of schizophrenia, and its associated cognitive impairment, especially immediate memory [115]. 
In fact, it has been suggested that the connecting link between depression and type 2 diabetes mellitus could be BDNF [116]. It is known that depression is a risk factor for the development of type 2 diabetes mellitus, while most patients with type 2 diabetes mellitus also have depression. This led to the suggestion that BDNF may play an important role linking depression and type 2 diabetes mellitus [116]. In this context, it is interesting to note that chronic alcohol ingestion may aggravate type 2 diabetes mellitus and lower BDNF level [117], implying that alcohol-induced peripheral neuropathy, dementia and decrease in cognitive function may also be due to low BDNF levels.

Decreased GABAergic (gamma-aminobutyric acid) neurons in the rat substantia nigra are observed in Huntington's disease, and may also occur in Parkinson's disease. BDNF is known to prevent excitotoxic killing of cultured GABA neurons. A continuous, 3-week supranigral infusion of BDNF prevented the loss of nigral neurons caused by the ibotenic acid-induced destruction of the caudate-putamen and globus pallidus, and BDNF increased nigral neuron size by $25 \%$. These effects were found to be specific to the TrkB tyrosine kinase receptor that mediates BDNF actions. These results suggest that exogenously administered BDNF can prevent neuronal loss, and diminish nigral neuron susceptibility to glutamate inputs [118], and thus may be of benefit in Huntington's and Parkinson's diseases. In this context, it is noteworthy that Huntingtin, a 350-kilodalton protein, is mutated in Huntington's disease. The mutant protein is presumed to acquire a toxic gain of function that is detrimental to striatal neurons in the brain. Loss of a beneficial activity of wild-type huntingtin may also cause the death of striatal neurons, leading to the development of Huntington's disease. It was reported [119] that wild-type huntingtin up-regulates transcription of BDNF, a pro-survival factor produced by cortical neurons that is necessary for survival of striatal neurons in the brain. This beneficial activity of huntingtin is lost when the protein becomes
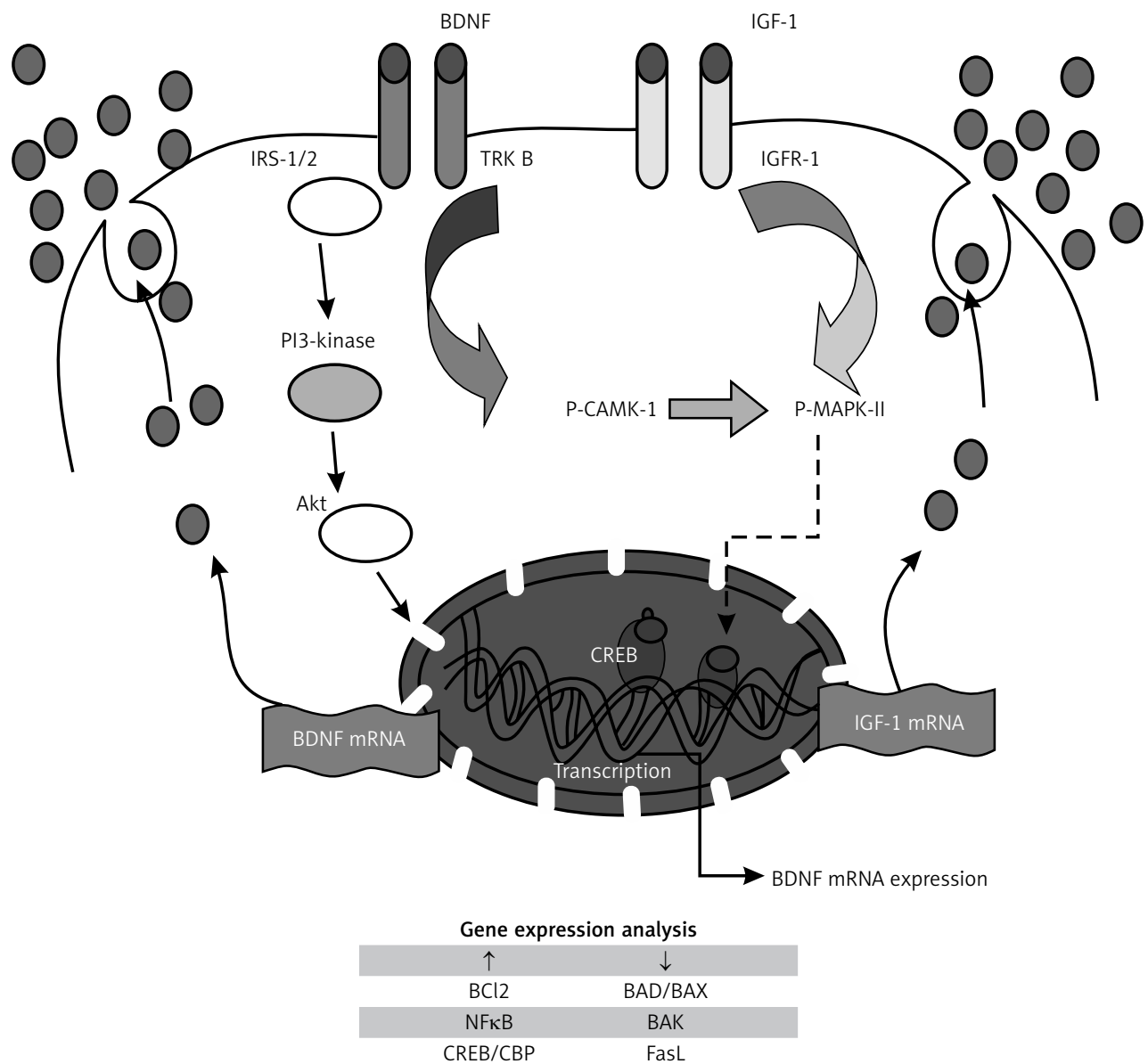

Figure 6. Possible mechanism(s) involved in cytoprotective action of BDNF. Sequential activation of insulin receptor substrate-1 (IRS-1/2), phosphatidylinositol-3-kinase (PI-3K) and protein kinase B (Akt) result in activation of pro-survival genes. IGF-1 and BDNF were shown to have similar downstream mechanisms, incorporating both CAMK and MAPK, which inactivate cell death machinery (Bad, BAX and FasL) and promote cell survival (Bcl2), neurogenesis and plasticity. Both BDNF and IGF mRNA are re-synthesized to form respective molecules which not only enhance insulin production but also inhibit apoptosis of $\beta$ cell machinery. This figure is adapted from refs. [108-110] 
mutated, resulting in decreased production of cortical BDNF. This leads to insufficient neurotrophic support for striatal neurons, which then die. These results indicate that restoring wild-type huntingtin activity to increase BDNF production and/or direct delivery of BDNF to the site of neuronal loss may be of therapeutic values in treating Huntington's disease and also in Parkinson's disease. Furthermore, it was noted that decreased BDNF expression observed in Huntington's disease exacerbates dopaminergic neuronal dysfunction [120], which may participate in the motor disturbances associated with this neurodegenerative disorder. These results were further supported by a report that reduced expression of the TrkB receptor occurs in Huntington's disease mouse models and in post-mortem human brain of patients who died from this disease [121].

3-Nitropropionic acid (3NP), when given over 5 days by constant systemic infusion using osmotic mini-pumps, produces striatal lesions that closely mimic some of the neuropathological features of Huntington's disease. Administration of sildenafil, a nitric oxide enhancer, improved neurologic scores, reduced neuronal loss and enhanced the expression of BDNF [122]. These data suggest that there is a close interaction between nitric oxide and BDNF and both these molecules protect neuronal loss and their enhancement could be of benefit in preventing Huntington's disease. These results coupled with the observation that BDNF overexpression in the forebrain rescues Huntington's disease phenotypes in YAC128 mice [123] indicates that attempts to restore striatal BDNF level may be of therapeutic benefit in Huntington's disease.

\section{Clinical significance of BDNF}

It is evident from the preceding discussion that BDNF has several important actions that could have significant clinical implications. Decrease in the expression of BDNF is seen in many neurological diseases such as Alzheimer's disease, Parkinson's disease, Huntington's disease and bipolar disease [124-133], as detailed above. Physical exercise enhances brain BDNF levels and thus improve in depression [134]. Lithium, which is used in bipolar disorder, is known to enhance TrkB activation and expression of BDNF mRNA [135], which supports the role of BDNF in bipolar disorder. Interestingly, overexpression of BDNF in the hippocampus was found to occur in spontaneous seizures, leading to temporal lobe epilepsy [136]. Furthermore, BDNF is synthesized and released in rabbit intestinal smooth muscle cells (SMCs) [137], which is influenced by release of calcium levels that, in turn, activate substance-P (SP) along with pituitary adenylate cyclase activating peptide (PACAP) [138]. BDNF can modulate gut function by activating the PLC pathway and hence could have therapeutic potential in the treatment of irritable bowel syndrome and functional dyspepsia [139, 140]. A significant decrease in the levels of BDNF-BCl2-Akt (genes involved in anti-apoptotic signaling pathways of BDNF) was observed in autism disorder [141]. Thus, plasma levels of BDNF may be used as a bio-marker for detection of autism disorder during early stages [142-145]. As already discussed above, BDNF has an important role in energy homeostasis that accounts for its role in obesity, type 2 diabetes mellitus and metabolic syndrome. BDNF, both by its peripheral and central actions, seems to be capable of preventing type 2 diabetes mellitus. It remains to be seen whether administration of BDNF could constitute a new therapeutic approach in the management of obesity, type 2 diabetes mellitus and metabolic syndrome, in both their prevention and management.

\section{Conclusions and future perspectives}

BDNF receptor activity not only enhanced neurogenesis but also suppressed apoptosis along with modulation in synaptic activity by a variety of signaling cascades. The participation of BDNF in the pathogenesis of cardiovascular diseases and diabetes mellitus by its critical role in inflammation, glucose and lipid metabolism is rather interesting. BDNF deficiency is associated with increased weight in mice and humans, and BDNF administration can reduce food intake and increase energy expenditure. Thus, BDNF seems to have an important role in several neurological diseases and type 2 diabetes mellitus.

The central role of BDNF as a cytoprotective molecule may explain why it is involved in neurological disorders and type 2 diabetes mellitus. In both instances, the ability of BDNF to protect neuronal cells and pancreatic $\beta$ cells seems to be the fundamental mechanism of its action. Yet, its precise role in brain development, physiology and pathology of neurological disorders is still not clear. Studies that investigate in depth the vascular and metabolic effects of BDNF and other neurotrophins in neural plasticity and survival may be crucial to understand the physiology of BDNF. In this context, it is noteworthy that BDNF is secreted by the gut and several other tissues, which suggests that it may have a role in several diseases including those of the gut. In future, attempts to increase local or systemic BDNF production by the use of co-factors such as vitamin $\mathrm{B}_{12}$ and dexamethasone, which are known to upregulate its expression [146], may be attempted while evaluating the clinical applications of BDNF 
in some of the clinical conditions in which it is likely to play a major role. A better understanding of the role of this endogenous peptide in health and disease may pave the way to exploit BDNF as a novel therapeutic agent for neurodegenerative and metabolic diseases.

\section{Acknowledgments}

Undurti N. Das is in receipt of a Ramalingaswami Fellowship of the Department of Biotechnology, New Delhi during the tenure of this study. Siresha Bathina is a senior research fellow of the Indian Council of Medical Research, New Delhi. This work was supported, in part, by grants from the Department of Biotechnology (DBT No. BT/ PR11627/MED/30/157/2010), Department of Science and Technology (No. IR/SO/LU/03/2008/1) under Intensification of Research in High Priority Areas (IRPHA), and Defence Research and Development Organisation, New Delhi ([TC/2519/INM - 03/2011/CARS] under R\&D Project INM-311) to UND. The funders had no role in study design, data collection and analysis, decision to publish, or preparation of the manuscript.

\section{Conflict of interest}

The authors declare no conflict of interest.

\section{References}

1. Binder DK, Scharfman HE. Brain-derived neurotrophic factor. Growth Factors 2004; 22: 123-31.

2. Acheson A, Conover JC, Fandl JP, et al. A BDNF autocrine loop in adult sensory neurons prevents cell death. Nature 1995; 374: 450-3.

3. Huang EJ, Reichardt LF. Neurotrophins: roles in neuronal development and function. Ann Rev Neurosci 2001; 24 677-736.

4. Maisonpierre PC, Le Beau MM, Ip NY, et al. Human and rat brain-derived neurotrophic factor and neurotrophin-3: gene structures, distributions, and chromosomal localizations. Genomics 1991; 10: 558-68.

5. Zigova T, Pencea V, Wiegand SJ, Luskin MB. Intraventricular administration of BDNF increases the number of newly generated neurons in the adult olfactory bulb. Mol Cell Neurosci 1998; 11: 234-45.

6. Benraiss A, Chmielnicki E, Lerner K, Roh D, Goldman SA. Adenoviral brain-derived neurotrophic factor induces both neostriatal and olfactory neuronal recruitment from endogenous progenitor cells in the adult forebrain. J Neurosci 2001; 21: 6718-31.

7. Scalzo P, Kümmer A, Bretas TL, Cardoso F, Teixeira AL. Serum levels of brain-derived neurotrophic factor correlate with motor impairment in Parkinson's disease. J Neurol 2010; 257: 540-5.

8. Sohrabji F, Lewis DK. Estrogen-BDNF interactions: implications for neurodegenerative diseases. Front Neuroendocrinol 2006; 27: 404-14.

9. Mughal MR, Baharani A, Chigurupati S, et al. Electroconvulsive shock ameliorates disease processes and extends survival in huntingtin mutant mice. Hum Mol Genet 2011; 20: 659-69.
10. Bothwell M. Functional interactions of neurotrophins and neurotrophins receptors. (Review). Annu Rev Neurosci 1995; 18: 223-53.

11. Klien R, Conway D, Parada LF, Barbacid M. The trkB tyrosine kinase gene codes for a second nuerogenic receptor that lacks catalytic domain. Cell 1990; 61: 647-56.

12. Klien R, Nanduri V, Jing SA, et al. The trkB tyrosine protein kinase is a receptor for brain-derived neurotrophic factor and NT-3. Cell 1991; 66: 395-403.

13. Thomas K, Davies A. Neurotrophins: a ticket to ride for BDNF. Curr Biol 2005; 15: 262-5.

14. Timmusk T, Palm K, Metsis M, et al. Multiple promoters direct tissue-specific expression of the rat BDNF gene. Neuron 1993; 10: 475-89.

15. Timmusk T, Lendahl U, Funakoshi H, Arenas E, Persson H, Metsis M. Identification of brain-derived neurotrophic factor promoter regions mediating tissue-specific, axotomy-, and neuronal activity-induced expression in transgenic mice. J Cell Biol 1995; 128: 185-99.

16. Liu QR, Lu L, Zhu XG, Gong JP, Shaham Y, Uhl GR. Rodent BDNF genes, novel promoters, novel splice variants, regulation by cocaine. Brain Res 2006; 1067: 1-12.

17. Aid T, Kazantseva A, Piirsoo M, Palm K, Timmusk T. Mouse and rat BDNF gene structure and expression revisited. J Neurosci Res 2007; 85: 525-35.

18. Gabriela B, Tongiorgi E. BDNF splice variants from the second promoter cluster support cell survival of differentiated neuroblastoma upon cytotoxic stress. J Cell Sci 2009: 122: 36-43.

19. Pruunsild P, Kazantseva A, Aid T, Palm K, Timmusk T. Dissecting the human BDNF locus: bidirectional transcription, complex splicing and multiple promoters. Genom ics 2007; 90: 397-406

20. Fang H, Chartier J, Sodja C, et al. Transcriptional activation of the human brain-derived neurotrophic factor gene promoter III by dopamine signaling in NT2/N neurons. J Biol Chem 2003; 278: 26401-9.

21. Kaplan DR, Miller FD. Neurotrophin signal transduction in the nervous system. Curr Opin Neurobiol 2000; 10: 381-91.

22. Patapoutian A, Reichardt LF. Trk receptors: mediators of neurotrophin action. Curr Opin Neurobiol 2001; 11: 272-80

23. Roux PP, Barker PA. Neurotrophin signaling through the p75 neurotrophin receptor. Progress Neurobiol 2002; 67: 203-33.

24. Barnabe-Heider F, Miller FD. Endogenously produced neurotrophins regulate survival and differentiation of cortical progenitors via distinct signaling pathways. J Neurosci 2003; 23: 5149-60.

25. Huang EJ, Reichardt LF. Trk receptors: roles in neuronal signal transduction. Annu Rev Biochem 2003; 72: 609-42.

26. Chao MV. Neurotrophins and their receptors: a convergence point for many signalling pathways. Nat Rev Neurosci 2003; 4: 299-309.

27. Kaplan DR, Miller FD. Signal transduction by the neurotrophin receptors. Curr Opin Cell Biol 1998; 9: 213-21.

28. Rhee S, Bae Y. Regulation of phosphoinositide-specific phospholipase C isozymes. J Biol Chem 1997; 272 15045-8.

29. Adcock MR, McGlade J, Mbamalu G, et al. Association of the Shc and $\mathrm{Grb} 2 / \mathrm{Sem} 5 \mathrm{SH} 2$-containing proteins is implicated in activation of the Ras pathway by tyrosine kinases. Nature 1998; 360: 689-92.

30. Mattson MP, Maudsley S, Martin B. BDNF and 5-HT: a dynamic duo in age-related neuronal plasticity and neurodegenerative disorders. Trends Neurosci 2004; 27: 589-94. 
31. Pezet S, Malcangio M, McMahon SB. B DNF: a neuromodulator in nociceptive pathways? Brain Res Rev 2002; 40: 240-9.

32. Bonni A, Brunet AE, West S, Datta R, Takasu MA, Greenberg ME. Cell survival promoted by the Ras-MAPK signaling pathway by transcription-dependent and -independent mechanisms. Science 1999; 286: 1358-62.

33. Brunet A, Bonni A, Zigmaond MJ. Akt promotes cell survival by phosphorylating and inhibiting a forkhead transcription factor. Cell 1999; 96: 857-68.

34. Vaillant AR, Mazzoni A, Tudan C, Boudreau M, Kaplan DR, Miller FD. Depolarization and neurotrophins converge on the phosphatidylinositol 3-kinase-Akt pathway to synergistically regulate neuronal survival. J Cell Biol 1999; 146: 955-66.

35. Corbit KC, Foster DA, Rosner MR. Protein kinase C mediates neurogenic but not mitogenic activation of mitogen-activated protein kinase in neuronal cells. Mol Cell Biol 1999; 19: 4209-18.

36. Rhee S, Bae Y. Regulation of phosphoinositide-specific phospholipase C isozymes. J Biol Chem 1997; 272 15045-8.

37. Dimitropoulou A, Bixby JL. Regulation of retinal neurite growth by alterations in MAPK/ERK kinase (MEK) activity. Brain Res 2000; 858: 205-14.

38. Leibrock J, Lottspeich F, Hohn A, et al. Molecular cloning and expression of brain-derived neurotrophic factor. Nature 1989; 341: 149-52.

39. Barde YA, Edgar D, Thoenen H. Purification of a new neurotrophic factor from mammalian brain. Embo J 1982; 1: 549-53.

40. Ernfors P, Lee KF, Jaenisch R. Mice lacking brain-derived neurotrophic factor develop with sensory deficits. Nature 1994; 368: 147-50.

41. Zafra F, Lindholm D, Castren E, Hartikka J, Thoenen H. Regulation of brain-derived neurotrophic factor and nerve growth factor mRNA in primary cultures of hippocampal neurons and astrocytes. J Neurosci 1992; 12 4793-9.

42. Lauterborn JC, Lynch G, Vanderklish P, Arai A, Gall CM. Positive modulation of AMPA receptors increases neurotrophin expression by hippocampal and cortical neurons. J Neurosci 2000; 20: 8-21.

43. Castrén E, Zafra F, Thoenen H, Lindholm D. Light regulates expression of brain-derived neurotrophic factor mRNA in rat visual cortex. Proc Natl Acad Sci USA 1992. 89: 9444-8.

44. Rocamora N, Welker E, Pascual M, Soriano E. Upregulation of BDNF mRNA expression in the barrel cortex of adult mice after sensory stimulation. J Neurosci 1996; 16: 4411-9.

45. Patterson SL, Grover LM, Schwartzkroin PA, Bothwell M. Neurotrophin expression in rat hippocampal slices: a stimulus paradigm inducing LTP in CA1 evokes increases in BDNF and NT-3 mRNAs. Neuron 1992; 9: 1081-8.

46. Neeper SA, Gómez-Pinilla F, Choi J, et al. Exercise and brain neurotrophins. Nature 1995; 373: 109.

47. Scharfman HE, Mercurio TC, Goodman JH, Wilson MA, MacLusky NJ. Hippocampal excitability increases during the estrous cycle in the rat: a potential role for brain-derived neurotrophic factor. J Neurosci 2003; 23: 11641-52.

48. Zafra F, Castren E, Thoenen H, Lindholm D. Interplay between glutamate and gamma-aminobutyric acid transmitter systems in the physiological regulation of brain-derived neurotrophic factor and nerve growth fac- tor synthesis in hippocampal neurons. Proc Natl Acad Sci U S A 1991; 88: 10037-41.

49. Zafra F, Hengerer B, Leibrock J, Thoenen H, Lindholm D. Activity dependent regulation of BDNF and NGF mRNAs in the rat hippocampus is mediated by non-NMDA glutamate receptors. Embo J 1990; 9: 3545-50.

50. Bozzi Y, Pizzorusso T, Cremisi F, Rossi FM, Barsacchi G, Maffei L. Monocular deprivation decreases the expression of messenger RNA for brain-derived neurotrophic factor in the rat visual cortex. Neuroscience 1995; 69: 1133-44.

51. Matayoshi S, Jiang N, Katafuchi T, et al. Actions of brain-derived neurotrophic factor on spinal nociceptive transmission during inflammation in the rat. J Physiol 2005; 569: 685-95.

52. Eibl JK, Chapelsky SA, Ross GM. Multipotent neurotrophins antagonist targets brain-derived neurotrophic factor and nerve growth factor. J Pharmacol Exp Therap 2009; 332: 446-54.

53. Canossa M, Giordano E, Cappello S, Guarnieri C, Ferri S. Nitric oxide down-regulates brain-derived neurotrophic factor secretion in cultured hippocampal neurons. Proc Natl Acad Sci U S A 2002; 99: 3282-7.

54. Zhang HT, Li LY, Zou XL, et al. The immunohistochemical distribution of NGF, BDNF, NT-3, NT-4 in the brains of adult Rhesus monkeys. J Histochem Cytochem 2007; 55: 1-19.

55. Raznahan A, Toro R, Proitsi P, et al. A functional polymorphism of the brain derived neurotrophic factor gene and cortical anatomy in autism spectrum disorder. J Neurodev Disord 2009; 1: 215-23.

56. Lommatzsch M, Zingler D, Schuhbaeck K, et al. The impact of age, weight and gender on BDNF levels in human platelets and plasma. Neurobiol Aging 2005; 26: 115-23.

57. Golden E, Emiliano A, Maudsley S, et al. Circulating brain-derived neurotrophic factor and indices of metabolic and cardiovascular health: data from the Baltimore Longitudinal Study of Aging. PLoS One 2010; 5: e10099.

58. Jung SH, Kim J, Davis JM, Blair SN, Cho HC. Association among basal serum BDNF, cardiorespiratory fitness and cardiovascular disease risk factors in untrained healthy Korean men. Eur J Appl Physiol 2011; 111: 303-11.

59. Krabbe KS, Mortensen EL, Avlund K, et al. Brain-derived neurotrophic factor predicts mortality risk in older women. J Am Geriatr Soc 2009; 57: 1447-52.

60. Bus BA, Molendijk ML, Penninx BJ, et al. Determinants of serum brain-derived neurotrophic factor. Psychoneuroendocrinology 2011; 36: 228-39.

61. Pillai AK, Bruno D, Sarreal AS. et al. Plasma BDNF levels vary in relation to body weight in females. PLoS One 2012; 7: e-39358.

62. Hofer MM, Barde YA. Brain-derived neurotrophic factor prevents neuronal death in vivo. Nature 1988; 331 : 261-2.

63. Noble EE, Billington CJ, Kotz CM, Wang C. The lighter side of BDNF. Am J Physiol Regul Integr Comp Physiol 2011; 300: R1053-69.

64. MCAllister AK, Lo DC, Katz LC. Neurotrophins regulate dendritic growth in developing visual cortex. Neuron 1995; 15: 791-803.

65. Klocker N, Kermer P, Weishaupt JH, Labes M, Ankerhold R, Bahr MJ. Brain-derived neurotrophic factor-mediated neuroprotection of adult rat retinal ganglion cells in vivo does not exclusively depend on phosphatidyl-inositol-3'-kinase/protein kinase B signaling. Neuroscience 2000; 20: 6962-7. 
66. Lee J, Seroogy KB, Mattson MP. Dietary restriction enhances neurotrophins expression and neurogenesis in the hippocampus of adult mice. J Neurochem 2002; 80: 539-47.

67. Kumar S, Parkash J, Kataria H, Kaur G. Interactive effect of excitotoxic injury and dietary restriction on neurogenesis and neurotrophic factors in adult male rat brain. Neurosci Res 2009; 65: 367-74.

68. Pencea V, Bingaman KD, Wiegand SJ, Luskin MB. Infusion of brain-derived neurotrophic factor into the lateral ventricle of the adult rat leads to new neurons in the parenchyma of the striatum, septum, thalamus, and hypothalamus. J Neurosci 2001; 21: 6706-17.

69. Ito H, Nakajima A, Nomoto H, Furukawa S. Neurotrophins facilitate neuronal differentiation of cultured neural stem cells via induction of mRNA expression of basic helix-loop-helix transcription factors Mash 1 and Math 1. J Neurosci Res 2003; 71: 648-58.

70. Bramham CR, Messaoudi E. BDNF function in adult synaptic plasticity: the synaptic consolidation hypothesis. Prog Neurobiol 2005; 76: 99-125.

71. Walz C, Jungling K, Lessmann V, Gottmann K. Presynaptic plasticity in an immature neocortical network requires NMDA receptor activation and BDNF release. J Neurophysiol 2006; 96: 3512-16.

72. Kramar EA, Chen LY, Lauterborn JC, Simmons DA Gall CM, Lynch G. BDNF upregulation rescues synaptic plasticity in middle-aged ovariectomized rats. Neurobiol Aging 2010; 33: 708-19.

73. Caldeira MV, Melo CV, Pereira DB, Carvalho RF, Carvalho $A L$, Duarte CB. BDNF regulates the expression and traffic of NMDA receptors in cultured hippocampal neurons. Mol Cell Neurosci 2007; 35: 208-19.

74. Bloodgood BL, Sabatini BL. Ca2+ signaling in dendritic spines. Current Opinion Neurobiol 2007; 17: 345-51.

75. Xu B, Gottschalk W, Chow A, et al. The role of brain-derived neurotrophic factor receptors in the mature hippocampus: modulation of long-term potentiation through a presynaptic mechanism involving trkB. J Neurosci 2000; 20: 6888-97.

76. Kuczewski N, Porcher C, Ferrand N, et al. Back propagating action potentials trigger dendritic release of BDNF during spontaneous network activity. J Neurosci 2008; 28: 7013-23.

77. Hartmann M, Heumann R, Lessmann V. Synaptic secretion of BDNF after high-frequency stimulation of glutamatergic synapses. EMBO J 2001; 20: 5887-97.

78. Donovan MJ, Miranda RC, Kraemer R, et al. Neurotrophin and neurotrophin receptors in vascular smooth mus cle cells. Regulation of expression in response to injury. Am J Pathol 1995; 147: 309-24.

79. Caporali A, Emanueli C. Cardiovascular actions of neurotrophins. Physiol Rev 2009; 89: 279-308.

80. Wang S, Bray P, McCaffrey T, March K, Hempstead BL, Kraemer R. p75(NTR) mediates neurotrophin-induced apoptosis of vascular smooth muscle cells. Am J Pathol 2000; 157: 1247-58.

81. Meuchel LW, Thompson MA, Cassivi SD, Pabelick CM, Prakash YS. Neurotrophins induce nitric oxide generation in human pulmonary artery endothelial cells. Cardiovasc Res 2011; 91: 668-76.

82. Leon A, Buriani A, Dal Toso R, et al. Mast cells synthesize, store, and release nerve growth factor. Proc Natl Acad Sci USA 1994; 9: 3739-43.

83. Steinmann L. Elaborate interactions between the immune and nervous systems. Nature Immunol 2004; 5: 575-81.
84. Barnes PJ. Neuroeffector mechanisms: the interface between inflammation and neuronal responses. J Allergy Clin Immunol 1996; 98: S73-81.

85. Golden E, Emiliano A, Maudsley S, et al. Circulating brain-derived neurotrophic factor and indices of metabolic and cardiovascular health: data from the Baltimore Longitudinal Study of Aging. PLoS One 2010; 5: e10099.

86. Pelleymounter MA, Cullen MJ, Wellman CL. Characteristics of BDNF-induced weight loss. Exp Neurol 1995; 131: 229-38.

87. Tsuchida A, Nonomura T, Nakagawa T, et al. Brain-derived neurotrophic factor ameliorates lipid metabolism in diabetic mice. Diabetes Obes Metab 2002; 4: 262-9.

88. Nakagawa T, Tsuchida A, Itakura Y, et al. Brain-derived neurotrophic factor regulates glucose metabolism by modulating energy balance in diabetic mice. Diabetes 2000; 49: 436-44.

89. Wu A, Ying Z, Gomez-Pinilla F. Dietary omega-3 fatty acids normalize BDNF levels, reduce oxidative damage, and counteract learning disability after traumatic brain injury in rats. J Neurotrauma 2004; 21: 1457-67.

90. Rosas-Vargas H, Martínez-Ezquerro JD, Bienvenu T. Brain-derived neurotrophic factor, food intake regulation, and obesity. Arch Med Res 2011; 42: 482-94.

91. Finkbeiner S. CREB couples neurotrophin signals to survival messages. Neuron 2000; 25: 11-4.

92. Jovanovic JN, Benfenati F, Siow YL, et al. Neurotrophins stimulate phosphorylation of synapsin I by MAP kinase and regulate synapsin I-actin interactions. Proc Natl Acad Sci USA 1996; 93: 3679-83.

93. Cao L, Lin EJ, Cahill MC, Wang C, Liu X, During MJ. Molecular therapy of obesity and diabetes by a physiological autoregulatory approach. Nat Med 2009; 15: 447-54.

94. Balkowiec A, Katz DM. Cellular mechanisms regulating activity-dependent release of native brain-derived neurotrophic factor from hippocampal neurons. J Neurosci 2002; 22: 10399-407.

95. Bariohay B, Lebrun B, Moyse E, Jean A. Brain-derived neurotrophic factor plays a role as an anorexigenic factor in the dorsal vagal complex. Endocrinology 2005; 146: 5612-20.

96. Byerly MS, Simon J, Lebihan-Duval E, Duclos MJ, Cogburn LA, Porter TE. Effects of BDNF, T3, and corticosterone on expression of the hypothalamic obesity gene network in vivo and in vitro. Am J Physiol Regul Integr Comp Physiol 2009; 296: R1180-9.

97. Cao L, Liu X, Lin EJ, et al. Environmental and genetic activation of a brain-adipocyte BDNF/leptin axis causes cancer remission and inhibition. Cell 2010; 142: 52-64.

98. Smith MA, Makino S, Kim SY, Kvetnansky R. Stress increases brain-derived neurotropic factor messenger ribonucleic acid in the hypothalamus and pituitary. Endocrinology 1995; 136: 3743-50.

99. Rios M, Fan G, Fekete C, et al. Conditional deletion of brain-derived neurotrophic factor in the postnatal brain leads to obesity and hyperactivity. Mol Endocrinol 2001; 15: 1748-57.

100. Kernie SG, Liebl DJ, Parada LF. BDNF regulates eating behavior and locomotor activity in mice. EMBO J 2000; 19: $1290-300$.

101. Das UN. Obesity: genes, brain, gut, and environment. Nutrition 2010; 26: 459-73.

102. Tsuchida A, Nonomura T, Ono-Kishino M, Nakagawa T, Taiji M, Noguchi $H$. Acute effects of brain-derived neurotrophic factor on energy expenditure in obese diabetic mice. Int J Obes Relat Metab Disord 2001; 25: 1286-93. 
103. Tonra JR, Ono M, Liu X, et al. Brain-derived neurotrophic factor improves blood glucose control and alleviates fasting hyperglycemia in C57BLKS-Lepr(db)/lepr(db) mice. Diabetes 1999; 48: 588-94.

104. Ono M, Itakura Y, Nonomura T, et al. Intermittent administration of brain-derived neurotrophic factor ameliorates glucose metabolism in obese diabetic mice. Metabolism 2000; 49: 129-33.

105. Nonomura T, Tsuchida A, Ono-Kishino M, Nakagawa T, Taiji $M$, Noguchi $H$. Brain-derived neurotrophic factor regulates energy expenditure through the central nervous system in obese diabetic mice. Int J Exp Diabetes Res 2001; 2: 201-9.

106. Krabbe KS, Nielsen AR, Krogh-Madsen R, et al. Brain-derived neurotrophic factor (BDNF) and type 2 diabetes. Diabetologia 2007; 50: 431-8.

107. Xu B, Goulding EH, Zang K, et al. Brain-derived neurotrophic factor regulates energy balance downstream of melanocortin-4 receptor. Nat Neurosci 2003; 6: 736-42.

108. Yamanaka M, Itakura $Y$, Inoue $T$, et al. Protective effect of brain-derived neurotrophic factor on pancreatic islets in obese diabetic mice. Metabolism 2006; 55: 1286-92.

109. Nakagawa T, Ogawa Y, Ebihara K, et al. Anti-obesity and anti-diabetic effects of brain-derived neurotrophic factor in rodent models of leptin resistance. Int J Obes Relat Disord 2003; 27: 557-65.

110. Ding Q, Vaynman S, Akhavan M, Ying Z, Gomez-Pinilla F. Insulin-like growth factor I interfaces with brain-derived neurotrophic factor-mediated synaptic plasticity to modulate aspects of exercise-induced cognitive function. Neuroscience 2006; 140: 823-33.

111. Zoladz JA, Pilc A, Majerczak J, Grandys M, ZapartBukowska J, Duda K. Endurance training increases plasma brain-derived neurotrophic factor concentration in young healthy men. J Physiol Pharmacol 2008; 59 Suppl. 7: 119-32.

112. Han X, Luo Y, Zhang X, et al. Rs4074134 near BDNF gene is associated with type 2 diabetes mellitus in Chinese Han population independently of body mass index. PLoS One 2013; 8: e56898.

113. He $M$, Wang J. Decreased serum brain-derived neurotrophic factor in Chinese patients with type 2 diabetes mellitus. Acta Biochim Biophys Sin (Shanghai) 2014; 46: 426-7.

114. Zhen YF, Zhang J, Liu XY, et al. Low BDNF is associated with cognitive deficits in patients with type 2 diabetes. Psychopharmacology (Berl) 2013; 227: 93-100.

115. Zhang XY, Liang J, Chen da C, et al. Low BDNF is associated with cognitive impairment in chronic patients with schizophrenia. Psychopharmacology (Berl) 2012; 222: 277-84.

116. Wang J, Zhao X, He M. Is BDNF biological link between depression and type 2 diabetes mellitus? Med Hypotheses 2012; 79: 255-8.

117. Jung $\mathrm{KI}$, Ju A, Lee $\mathrm{HM}$, et al. Chronic ethanol inges tion, type 2 diabetes mellitus, and brain-derived neurotrophic factor (BDNF) in rats. Neurosci Lett 2011; 487: 149-52.

118. Volpe BT, Wildmann J, Altar CA. Brain-derived neuro trophic factor prevents the loss of nigral neurons in duced by excitotoxic striatal-pallidal lesions. Neuroscience 1998; 83: 741-8.

119. Zuccato C, Ciammola A, Rigamonti D, et al. Loss of huntingtin-mediated BDNF gene transcription in Huntington's disease. Science 2001; 293: 493-8.

120. Pineda JR, Canals JM, Bosch M, et al. Brain-derived neurotrophic factor modulates dopaminergic deficits in a transgenic mouse model of Huntington's disease. J Neurochem 2005; 93: 1057-68.

121. Ginés S, Bosch M, Marco S, et al. Reduced expression of the TrkB receptor in Huntington's disease mouse models and in human brain. Eur J Neurosci 2006; 23: 649-58.

122. Puerta E, Hervias I, Barros-Miñones L, et al. Sildenafil protects against 3-nitropropionic acid neurotoxicity through the modulation of calpain, CREB, and BDNF. Neurobiol Dis 2010; 38: 237-45.

123. Xie Y, Hayden MR, Xu B. BDNF overexpression in the forebrain rescues Huntington's disease phenotypes in YAC128 mice. J Neurosci 2010; 30: 14708-18.

124. Mattson MP, Maudsley S, Martin B. A neural signaling triumvirate that influences ageing and age-related disease: insulin/IGF-1, BDNF and serotonin. Ageing Res Rev 2004; 3: 445-64.

125. Bonni A, Brunet A, West AE, Datta SR, Takasu MA, Greenberg ME. Cell survival promoted by the RasMAPK signaling pathway by transcription-dependent and independent mechanisms. Science 2009; 286; 1358-62.

126. D'Mello SR, Borodezt K, Soltoff SP. Insulin-like growth factor and potassium depolarization maintain neuronal survival by distinct pathways: possible involvement of PI 3-kinase in IGF-1 signaling. J Neurosci 1997; 17: 1548-60.

127. Zuccato C, Cattaneo E. Brain-derived neurotrophic factor in neurodegenerative diseases. Nat Rev Neurol 2009; 5: 311-22.

128. Zuccato C, Valenza M, Cattaneo E. Molecular mechanisms and potential therapeutical targets in Huntington's disease. Physiol Rev 2010; 90: 905-81.

129. Murer MG, Yan Q, Raisman-Vozari R. Brain-derived neurotrophic factor in the control human brain, and in Alzheimer's disease and Parkinson's disease. Prog Neurobiol 2001; 63: 71-124.

130. Ferrer I, Marín C, Rey MJ, et al. BDNF and full-length and truncated TrkB expression in Alzheimer disease. Implications in therapeutic strategies. J Neuropathol Exp Neurol 1999; 58: 729-39.

131. Phillips HS, Hains JM, Armanini M, Laramee GR, Johnson SA, Winslow JW. BDNF mRNA is decreased in the hippocampus of individuals with Alzheimer's disease. Neuron 1991; 7: 695-702.

132. Howells DW, Porritt MJ, Wong JY, et al. Reduced BDNF mRNA expression in the Parkinson's disease substantia nigra. Exp Neurol 2000; 166: 127-35.

133. Zuccato C, Ciammola A, Rigamonti D, et al. Loss of huntington-mediated BDNF gene transcription in Huntington's disease. Science 2001; 293: 493-8.

134. Smith MA, Makino S, Kvetnansky R, Post RM. Stress and glucocorticoids affect the expression of brain-derived neurotrophic factor and neurotrophin-3 mRNAs in the hippocampus. J Neurosci 1995; 15: 1768-77.

135. Pedersen BK, Pedersen M, Krabbe KS, Bruunsgaard $H$, Matthews VB, Febbraio MA. Role of exercise-induced brain-derived neurotrophic factor production in the regulation of energy homeostasis in mammals. Exp Physiol 2009; 94: 1153-60.

136. Hashimoto R, Takei N, Shimazu K, Christ L, Lu B, Chuang DM. Lithium induces brain-derived neurotrophic factor and activates TrkB in rodent cortical neurons: an essential step for neuroprotection against glutamate excitotoxicity. Neuropharmacology 2002; 43: 1173-9.

137. Takahashi M, Hayashi S, Kakita A, et al. Patients with temporal lobe epilepsy show an increase in brain-derived neurotrophic factor protein and its correlation with neuropeptide Y. Brain Res 1999; 818: 579-82. 
138. Alqudah M, Mahavedi S, Zachary BL, Kay JC, Murthy SK, Grider JR. Pituitary adenylate cyclase-activating peptide (PACAP) and substance $P$ (SP) induce the release of brain-derived neurotropic factor (BDNF) from the longitudinal muscle layer of the intestine. FASEB J 2011; 25: 1070-4.

139. Fukuchi M, Tabuchi A, Tsuda M. Transcriptional regulation of neuronal genes and its effect on neural functions: cumulative mRNA expression of PACAP and BDNF genes controlled by calcium and cAMP signals in neurons. J Pharma Sci 2005; 98: 212-8.

140. Sariola $H$. The neurotrophic factors in non-neuronal tissues. Cell Mol Life Sci 2001; 58: 1061-6.

141. Mayer EA, Tillisch K, Bradesi S. Modulation of the braingut axis as a therapeutic approach in gastrointestinal disease. Aliment Pharmacol Therap 2006; 6: 919-33.

142. Sheikh AM, Malik M, Wen G, et al. BDNF-Akt-Bcl2 antiapoptotic signaling pathway is compromised in the brain of autistic subjects. J Neurosci Res 2010; 88: 2641-7.

143. Raznahan A, Toro R, Proitsi P, et al. A functional polymorphism of the brain derived neurotrophic factor gene and cortical anatomy in autism spectrum disorder. J Neurodev Disord 2009; 1: 215-23.

144. Das UN. Autism as a disorder of deficiency of brain-derived neurotrophic factor and altered metabolism of polyunsaturated fatty acids. Nutrition 2013; 29: 1175-85.

145. Das UN. Nutritional factors in the pathobiology of autism. Nutrition 2013; 29: 1066-9.

146. Sun H, Yang T, Li Q, et al. Dexamethasone and vitamin B12 synergistically promote peripheral nerve regeneration in rats by upregulating the expression of brain-derive neurotrophic factor. Arch Med Sci 2012; 8: 924-30. 